\title{
Two new species and one newly recorded species of Elaphropeza Macquart from Taiwan (Diptera, Empididae,Tachydromiinae)
}

\author{
Jinjing Wang ${ }^{1, \dagger}$, Lili Zhang ${ }^{2, \ddagger}$, Ding Yang ${ }^{1, \S}$ \\ I Department of Entomology, China Agricultural University, Beijing 100193, China 2 Key Laboratory of the \\ Zoological Systematics and Evolution, Institute of Zoology, Chinese Academy of Sciences, Beijing 100101, China \\ † urn:lsid:zoobank.org:author:D4E9A448-1DCF-43B1-A23C-6E11C84299B7 \\ † urn:lsid:zoobank.org:author:6246660E-004A-4198-B4A4-2724B4953397 \\ § urn:lsid:zoobank.org:author:FD9077E0-D8D5-4A3A-80FD-2862726AA066
}

Corresponding author: Ding Yang (dyagncau@126.com; dyangcau@yahoo.com.cn); Lili Zhang (zhll@ioz.ac.cn)

Academic editor: Martin Hauser | Received 25 April 20112 | Accepted 13 June 2012 | Published 20 June 2012

urn:lsid:zoobank.org:pub:E2C6D5F0-CB7E-42D0-AC5B-D54AE5B7A8FB

Citation: Wang J, Zhang L, Yang D (2012) Two new species and one newly recorded species of Elaphropeza Macquart from Taiwan (Diptera, Empididae, Tachydromiinae). ZooKeys 203: 15-25. doi: 10.3897/zookeys.203.3284

\begin{abstract}
Previously 11 Elaphropeza species were known from Taiwan. The following two species of the genus Elaphropeza are described: Elaphropeza flaviscutum sp. n. and E. trimacula sp. n. One species, Elaphropeza plumata Yang, Merz \& Grootaert, is newly recorded from Taiwan. A key to 14 known species of Elaphropeza from Taiwan is presented.
\end{abstract}

\section{Keywords}

Diptera, Empididae, Tachydromiinae, Elaphropeza, new species

\section{Introduction}

Elaphropeza Macquart is a large genus in the subfamily Tachydromiinae traditionally placed in the family Empididae (Melander 1928; Steyskal and Knutson 1981; Woodley 1989; Yang et al. 2007; Cumming and Sinclair 2009) or assigned to the family Hybotidae (Chvála 1983; Sinclair and Cumming 2006; Chvála and Kovalev 1989; Shamshev

Copyright Jinjing Wang et al. This is an open access article distributed under the terms of the Creative Commons Attribution License 3.0 (CC-BY), which permits unrestricted use, distribution, and reproduction in any medium, provided the original author and source are credited. 
and Grootaert 2007). Elaphropeza is very similar to Drapetis Meigen and was originally considered as a subgenus of the latter genus. It can be separated from Drapetis by the following features: occiput more convex; antenna not upturned; first flagellomere conical with lower margin as straight as upper margin; mesopleuron bare; hind tibia usually with 1-2 antero-dorsal setae (Collin 1961; Chvála 1975; Yang and Gaimari 2005; Shamshev and Grootaert 2007; Cumming and Sinclair 2009). It is distributed worldwide with 212 known species (Yang et al. 2007; Shamshev and Grootaert 2007; Grootaert and Shamshev 2012). The species from the Chinese mainland were reviewed by Yang and Gaimari (2005), and the Oriental species were reviewed by Shamshev and Grootaert (2007). Eleven species of the genus were known from Taiwan (Yang et al. 2007; Shamshev and Grootaert 2007). In this study three species including two new species of Elaphropeza are added to the fauna of Taiwan. A key to 14 known species of Elaphropeza from Taiwan is presented.

\section{Material and methods}

The terminology follows Shamshev and Grootaert (2007). The types are deposited in Entomological Museum of China Agricultural University (CAU), Beijing. The following abbreviations for setae are used: acr-acrostichal, ad-anterodorsal, av-anteroventral, dc-dorsocentral, h-humeral, npl-notopleural, oc-ocellar, prsc-prescutellar, psa-postalar, pv-posteroventral, sc-scutellar, vt-vertical.

\section{Key to species of Elaphropeza from Taiwan}

1 Head black 2

- Head yellow Elaphropeza xanthocephala Bezzi Hind tibia with 1-2 ad 3 Hind tibia without ad Elaphropeza trimacula sp. n. Hind tibia with 1 ad . .4

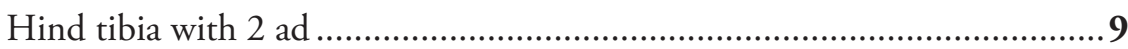

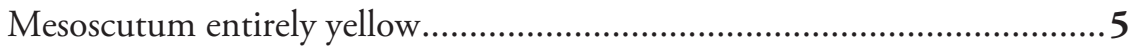

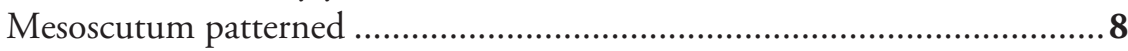

- $\quad$ Hind tibia with long pointed apical projection Scutellum brown medially

Arista very long, at least twice as long as basal three segments; acr biseriate, dc uniseriate 
Arista not thickened; mesoscutum pattern not as below.

Elaphropeza pictithorax Bezzi

- $\quad$ Arista thickened with plumose pubescence; mesoscutum with two small lateral spots and one large mid-posterior spot

9 Mesoscutum entirely yellow ......................................................... 10

- Mesoscutum patterned..................................................................... 12

10 Scutellum black at middle or entirely blackish .................................... 11 Scutellum entirely yellow..... Elaphropeza formosae Bezzi

11 Scutellum black at middle; hypopleuron yellow, metapleuron brownish at upper part. Elaphropeza scutellaris Bezzi

- Scutellum entirely black; hypopleuron black except narrow lower portion, metapleuron entirely yellow Elaphropeza flaviscutum sp. n.

12 Hind tibia with indistinct, rounded projection 13 Hind tibia with long pointed apical projection

Elaphropeza longicalcaris (Saigusa)

13 Scutellum wholly black Elaphropeza lanuginosa Bezzi Scutellum black at middle.... Elaphropeza scutellaris Bezzi

\section{Taxonomy}

\section{Elaphropeza flaviscutum sp. $\mathrm{n}$.}

urn:lsid:zoobank.org:act:1A8DFF1F-A5BF-4D4A-82C6-D217BD5B2ACD http://species-id.net/wiki/Elaphropeza_flaviscutum

Figs 1-2, 5-7

Diagnosis. Mesoscutum entirely yellow; scutellum entirely blackish; postnotum entirely blackish. Thoracic pleuron with only hypopleuron black except lower portion. Left surstylus large and broad; left cercus long with swollen apex.

Description. Male. Body length 2.4-2.6 mm, wing length 2.2-2.5 mm.

Head black with pale gray pollinosity. Setulae and setae on head brownish yellow. Eyes contiguous on face. Ocellar tubercle with 2 oc and 2 short posterior setulae; $1 \mathrm{vt}$ curved inward, slightly longer than oc. Antenna brown except scape and pedicel yellow; scape bare, shorter than pedicel; pedicel with circlet of blackish apical setulae; 1 st flagellomere short, conical, 2.0 times longer than wide, short pubescent; arista long (4 times longer than 1st flagellomere), dark brown, short pubescent. Proboscis brownish yellow with blackish setulae; palpus yellow with blackish setulae and 1 blackish apical seta.

Thorax mostly yellow with thin pale gray pollinosity; mesoscutum lacking dark spots; scutellum and postnotum blackish, laterotergite yellow; hypopleuron black except lower portion, metapleuron without spot. Setulae and setae on thorax blackish; mesoscutum with sparse setulae; $\mathrm{h}$ absent, $2 \mathrm{npl}$ (posterior npl longer), $1 \mathrm{sa}, 1 \mathrm{psa}$, biseriate acr, uniseriate $\mathrm{dc}$ and 1 long strong posteriormost dc; scutellum with two pairs of sc (basal pair very 


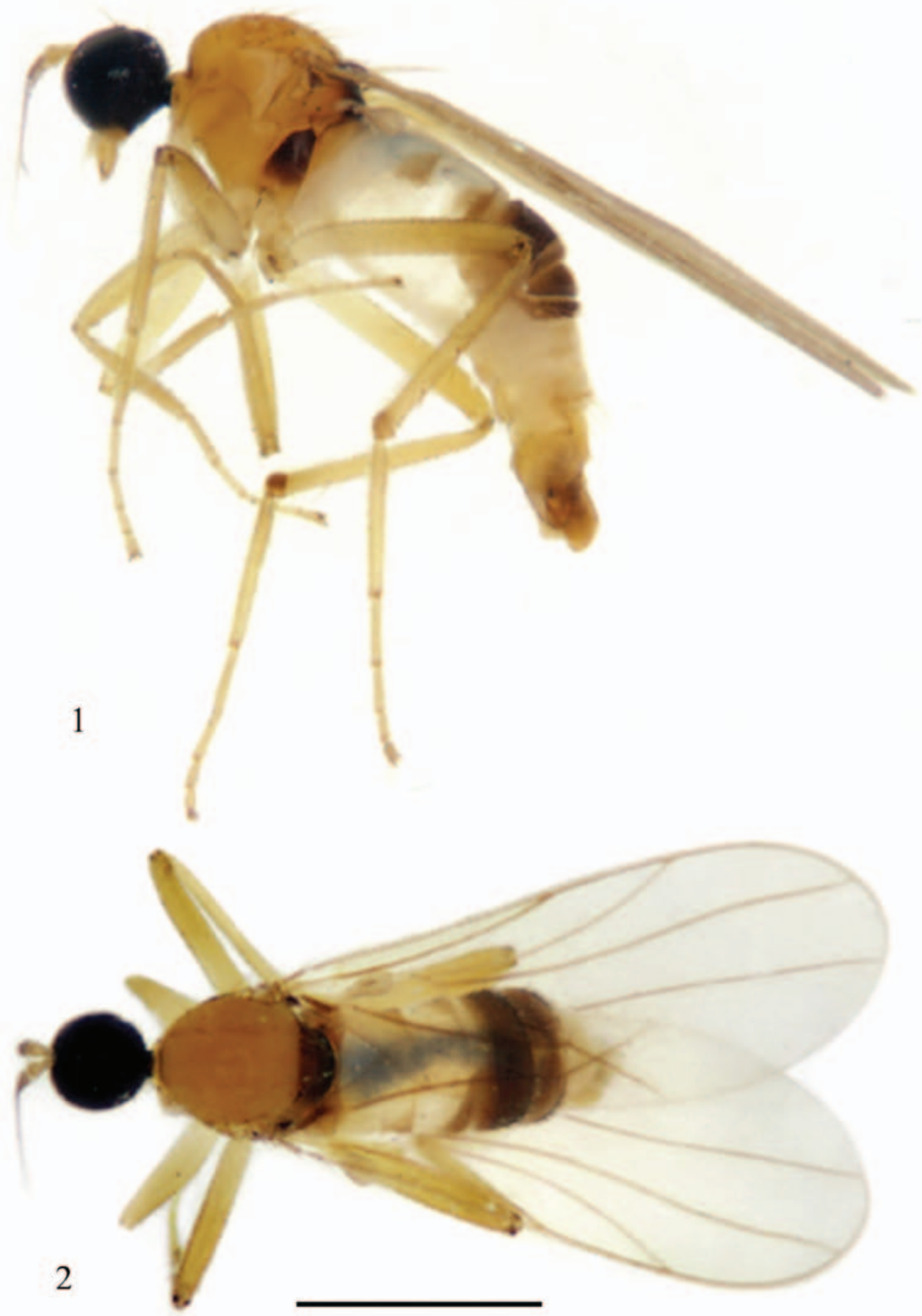

Figures I-2. Elaphropeza flaviscutum sp. n. I adult, lateral view $\mathbf{2}$ adult, dorsal view. Scale bar $1 \mathrm{~mm}$. 
short, about $1 / 4$ as long as apical pair). Legs yellow. Setulae and setae on legs blackish; fore coxa with 2 anterior setae at base, apically with 2 anterior setae; mid coxa apically with 3 anterior setae; hind coxa with 1 outer seta at apical margin. Fore femur 1.1 times as thick as mid femur, mid and hind femora subequal in thickness. Fore and mid femora each with 1 long thin pv at extreme base; mid femur with 1 preapical anterior seta; hind femur with 3 weak ad at base. Fore tibia apically with 1 av and 1 pv; mid tibia with row of short spinelike brown ventral setae, apically with 1 av and 1 pv; hind tibia with 2 ad, apically with 1 av. Hind tarsomere 1 without distinct ventral setae. Wing hyaline, veins dark brown, crossvein m-cu nearly vertical. Calypter brown with blackish setulae. Halter brown.

Abdomen mostly yellow with thin pale gray pollinosity; tergite 1 wholly membranous; tergites 2-3 brown, each with pair of subtrianglur lateral sclerites brown, medially linear and interrupted; tergite 4 broadest and tergite 5 narrow, blackish; tergite 5 anteriorly with large, separated, bare, blackish sclerite hidden within tergite 4; hypopygium dark brownish yellow. Setulae and setae on abdomen blackish except tergites 4-5 each with group of short squamiform black setae laterally, tergite 7 with row of long setae at posterior margin.

Male genitalia (Figs 5-7): Left epandrial lobe rather narrow in dorsal view, with surstylus large and broad in lateral view. Right epandrial lobe rather large in dorsal view, fused with apically narrowed surstylus. Left cercus long with swollen apex; right cercus rather short, about $1 / 3$ as long left cercus.

Female. Unknown.

Type material. Holotype male, Taiwan, Nantou, Lianhuachi (120.8900E, 23.9260N), 2010. XI.11, Ding Yang. Paratype 2 males, same data as holotype. These specimens were collected from tropical forest by sweep net.

Distribution. China (Taiwan).

Etymology. The specific name refers to the yellow scutum.

Remarks. This new species belongs to E. ephippiata group, and is similar to E. scutellaris Bezzi from Taiwan of China, but may be separated from the latter by the scutum entirely yellow, scutellum and postnotum entirely blackish, hypopleuron black except narrow lower portion and metapleuron without spot. In E. scutellaris, the scutum usually has the indistinct vittae; the scutellum and postnotum are yellow with brownish spot in middle; the hypopleuron has no spot, the metapleuron is brownish at the upper part (Bezzi 1912; Shamshev and Grootaert 2007).

\section{Elaphropeza plumata Yang, Merz \& Grootaert}

http://species-id.net/wiki/Elaphropeza_plumata

Elaphropeza plumata Yang, Merz \& Grootaert, 2006: 575. Type locality: China: Guangdong, Zijing.

Diagnosis. Arista thick with plumose pubescence. Mesoscutum with two small lateral spots and one large mid-posterior spot. Abdominal tergites 3-5 without short squamiform setae. 
Specimen examined. 1 female, Taiwan, Jiayi, Shuisheliao (120.6595E, 23.6544N), $1165 \mathrm{~m}, 2010$. XI. 16, Ding Yang. This specimen was collected from tropical forest by sweep net.

Distribution. China (Guangdong, Taiwan).

Remarks. This can be easily distinguished from other known species of the genus by the thick arista and unique marking pattern of the mesoscutum.

\section{Elaphropeza trimacula sp. n.}

urn:lsid:zoobank.org:act:1EB36F18-11CA-4C67-B43D-911A6220D062

http://species-id.net/wiki/Elaphropeza_trimacula

Figs 3-4, 8-10

Diagnosis. Arista with distinct pubescence. Mesoscutum with three black spots. Hind tibia without ad. Left cercus rather large with 7 long strong apical setae.

Description. Male. Body length $2.3 \mathrm{~mm}$, wing length $2.5 \mathrm{~mm}$.

Head black with pale gray pollinosity. Setulae on head yellow, setae brownish yellow. Eyes contiguous on face. Ocellar tubercle with 2 oc and 2 short posterior setulae; 2 vt curved inward, outer vt shorter than inner vt. Antenna dark brown except scape and pedicel yellow; scape bare, shorter than pedicel; pedicel with circlet of blackish apical setulae; 1 st flagellomere long, conical, 2.4 times longer than wide, short pubescent; arista long (3.6 times longer than 1st flagellomere), dark brown, distinctly pubescent. Proboscis dark brownish yellow with blackish setulae; palpus yellow with blackish setulae and 1 blackish apical seta.

Thorax mostly yellow with thin pale gray pollinosity; mesoscutum with three blackish spots, median spot running through entire scutum and wider anteriorly; scutellum and postnotum black; pleuron with posterior portion (including hypopleuron, metapleuron and posterior portion of pteropleuron) black, mesopleuron and sternopleuron each with a blackish spot. Setulae on thorax yellow, setae brownish yellow; mesoscutum with short dense setulae; h absent, $2 \mathrm{npl}$ (posterior npl longer), 1 prsc, 1 sa, 1 psa, acr and dc multiseriate and uniformly short; scutellum with two pairs of sc (basal pair very short, about $1 / 4$ as long as apical pair). Legs yellow except fore tibia and tarsus brown, mid tarsus and hind tarsomere 5 brownish yellow. Setulae and setae on legs blackish; fore coxa with 2 anterior setae at base, apically with 2 anterior setae; mid coxa apically with 3 anterior setae; hind coxa with 1 outer seta at apical margin. Fore femur 1.1 times as thick as mid femur, fore and hind femora subequal in thickness. Fore and mid femora each with row of short thin pv, and 1 long thin pv at extreme base; mid femur with 1 preapical anterior seta; hind femur with 3 weak ad at base. Fore tibia apically with 1 av and $1 \mathrm{pv}$; mid tibia with row of short spine-like black ventral setae, apically with 1 short av and 1 long pv; hind tibia without ad, apically with 1 av. Hind tarsomere 1 with 4-5 very short, irregular av. Wing hyaline, slightly uniformly tinged grayish; veins dark brown, crossvein m-cu oblique. Calypter brown with blackish setulae. Halter brown. 

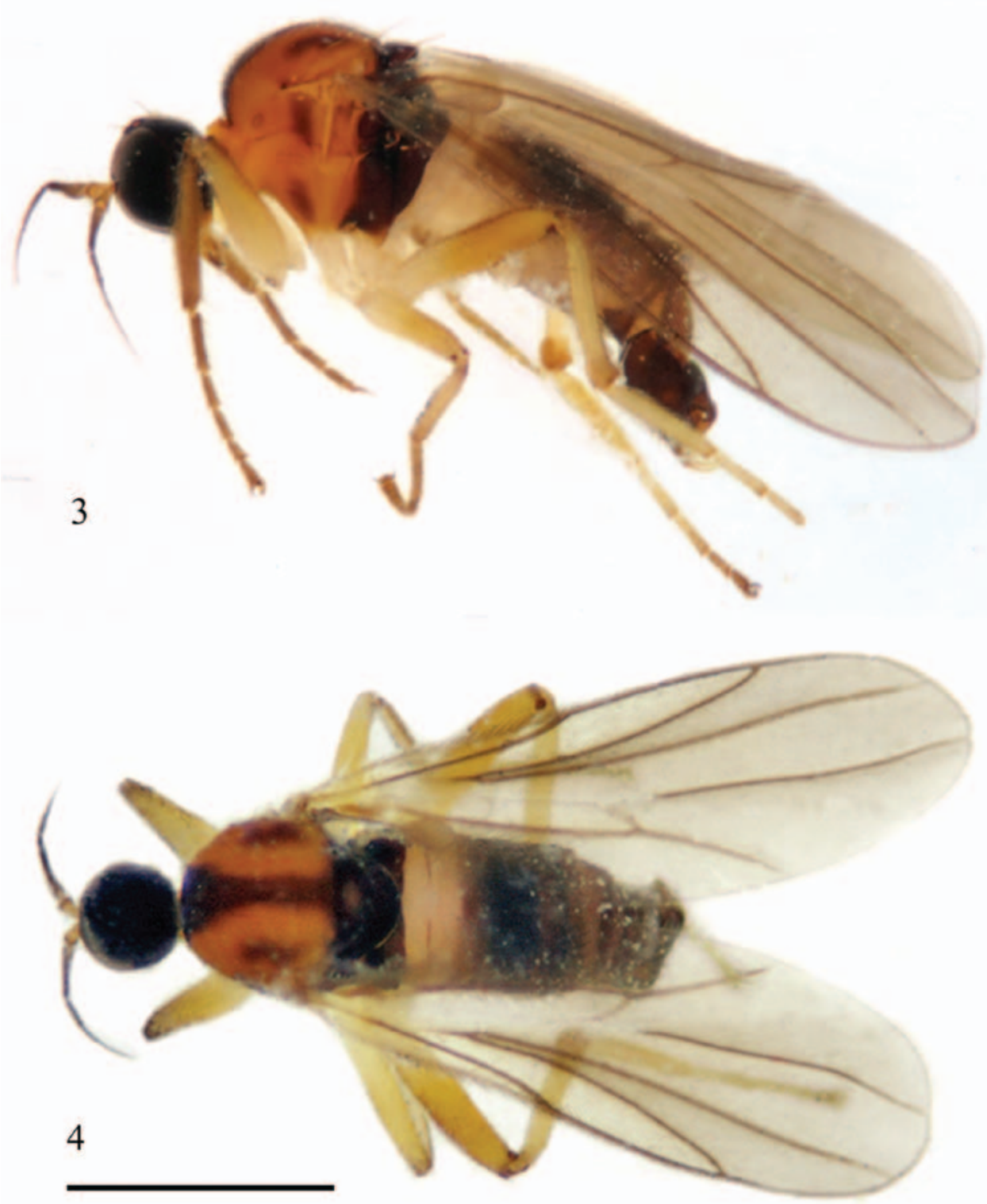

Figures 3-4. Elaphropeza trimacula sp. n. 3 adult, lateral view 4 adult, dorsal view. Scale bar $1 \mathrm{~mm}$.

Abdomen dark brown with thin pale gray pollinosity; tergites complete except tergite 1 linear; tergite 3 relatively board, blackish; hypopygium blackish. Setulae and setae on abdomen blackish except tergites 3-5 each with group of short squamiform black setae laterally, tergite 7 with row of long setae at posterior margin.

Male genitalia (Figs 8-10): Left epandrial lobe rather narrow, with surstylus finger-like and apically curved inward in dorsal view. Right epandrial lobe rather large 


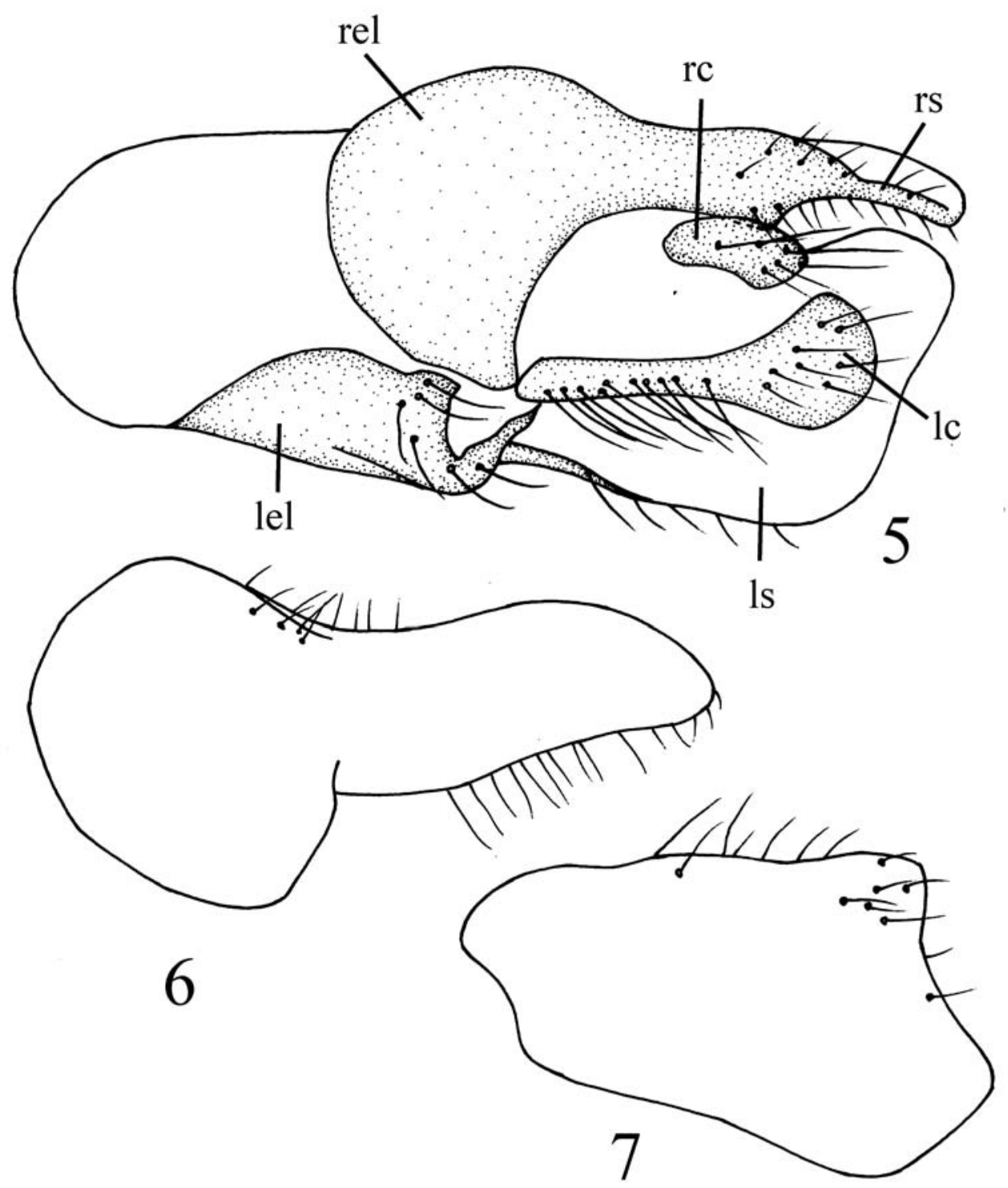

Figures 5-7. Elaphropeza flaviscutum sp. n. 5 male genitalia, dorsal view $\mathbf{6}$ right epandrial lobe $\mathbf{7}$ left surstylus. Scale bar $0.25 \mathrm{~mm}$. Abbreviations: $\mathbf{l c}=$ left cercus; lel = left epandrial lobe; $\mathbf{l} \mathbf{s}=$ left surstylus.

and broad, fused with surstylus of complicated shape. Left cercus rather long and large with 7 long strong apical setae. Right cercus very small (about 1/10 as long as left cercus), short finger-like.

Female. Unknown.

Type material. Holotype male, Taiwan, Taoyuan, Tamanshan (121.4507E, 24.7058 N), $1620 \mathrm{~m}, 2011$. VI. 14, Xiaoyan Liu. This specimen was collected from tropical forest by sweep net. 

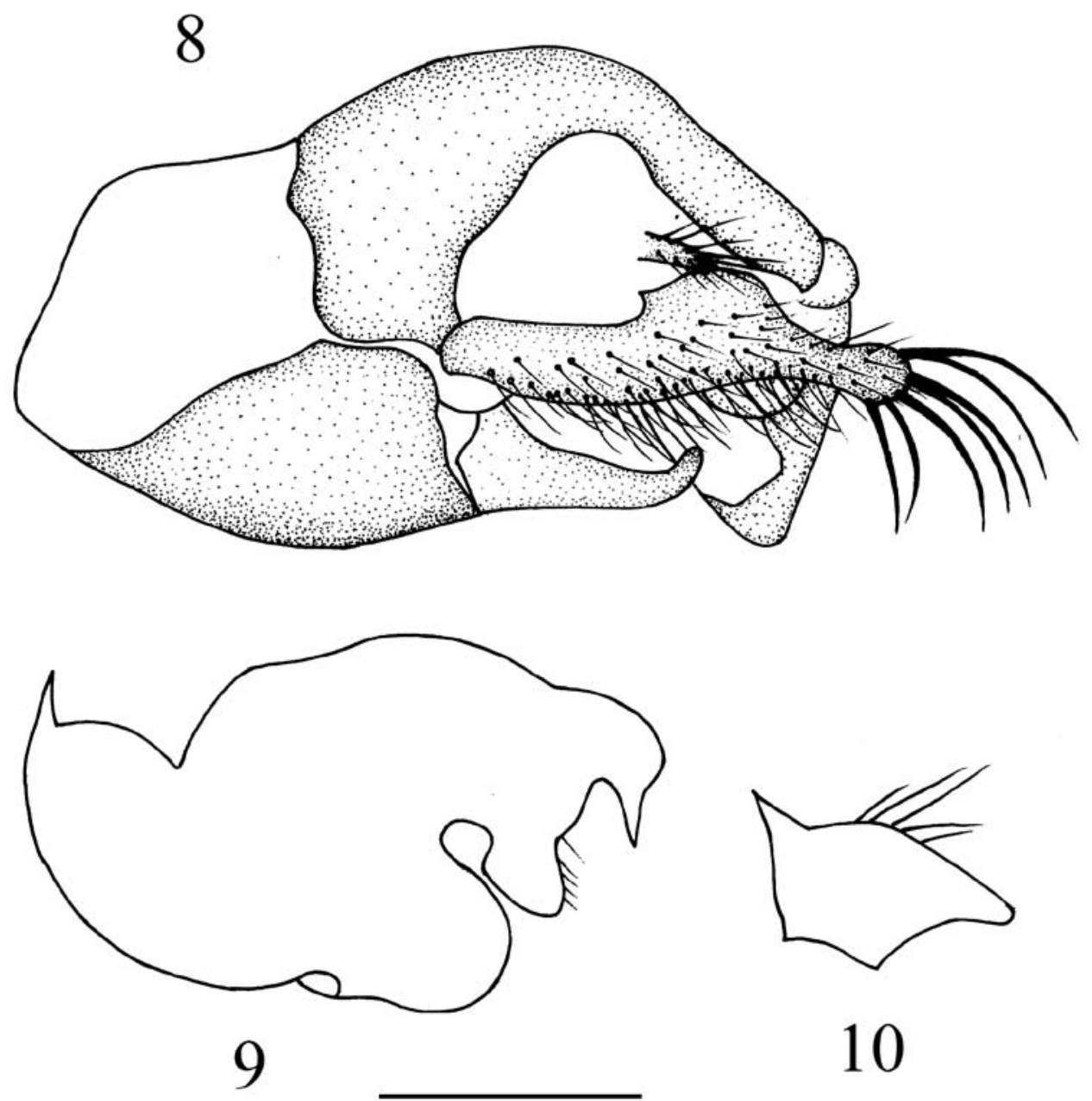

Figures 8-10. Elaphropeza trimacula sp. n. 8 male genitalia, dorsal view 9 right epandrial lobe $\mathbf{1 0}$ left surstylus. Scale bar $0.25 \mathrm{~mm}$.

Distribution. China (Taiwan).

Etymology. The specific name refers to the mesoscutum with three spots.

Remarks. This new species belongs to E. biuncinata group. In the key of Shamshev and Grootaert (2007), this species runs to E. acanthi Shamshev \& Grootaert from Singapore, but may be separated from the latter by the mesoscutum with three spots, the first flagellomere relatively long (2.4 times longer than wide), and arista with the distinct pubescence. In $E$. acanthi, the mesoscutum has only one middle spot, the first flagellomere is relatively short (2.0 times longer than wide), and the arista is clothed in very short pubescence (Shamshev and Grootaert 2007). 


\section{Acknowledgements}

Our sincere thanks are due to Prof. Shen-Horn Yen (National Sun Yat-Sen University, Kaohsiung) for his kind help during the survey in Taiwan in 2011 and 2012, and Dr. Xiaoyan Liu for collecting the specimen of E. trimacula. Three anonymous reviewers are thanked for providing useful comments on an earlier draft of this paper. The research was funded by the National Natural Science Foundation of China (Nos. 30970395) and the Doctoral Program of Higher Education of China (20090008110016).

\section{References}

Bezzi M (1912) Rhagionidae et Empididae ex Insula Formosa a Clar. H. Sauter Missae. Annales Historico-Naturalies Musei Nationalis Hungarici 10: 442-495.

Collin JE (1961) Empididae. British Flies 6. Cambridge University Press, Cambridge, 782pp.

Chvála M (1975) The Tachydromiinae (Dipt. Empididae) of Fennoscandia and Denmark. Fauna Entomologica Scandinavica 3: 1-336.

Chvála M (1983) The Empidoidea (Diptera) of Fennoscandia and Denmark. II. General Part. The families Hybotidae, Atelestidae and Microphoridae. Fauna Entomologica Scandinavica 12: 1-279.

Chvála M, Kovalev KV (1989) Family Hybotidae. In: Soós A, Papp L (Eds) Catalogue of Palaearctic Diptera 6. Elsevier Science Publishers \& Akademiai Kiado, Amsterdam \& Budapest, $174-227$.

Cumming J M and Sinclair B J (2009) Empididae (dance flies, balloon flies, predaceous flies). In: Brown BV, Borken A, Cumming JM, Wood DM, Woodley NE, Zumbado MA (Eds) Manual of Central American Diptera. Vol. 1. NRC Research Press, Ottawa, 653-670.

Grootaert P, Shamshev IV (2012) The fast-running flies (Diptera, Hybotidae, Tachydromiinae) of Singapore and adjacent regions. European Journal of Taxonomy 5: 1-162.

Melander AL (1928) Diptera, Fam. Empididae. In: Wytsman P (Ed) Genera Insectorum, 1927 185. Louis Desmet-Verteneuil, Bruxelles, 434 pp.

Shamshev IV, Grootaert P (2007) Revision of the genus Elaphropeza Macquart (Diptera: Hybotidae) from the Oriental Region, with a special attention to the fauna of Singapore. Zootaxa 1488: 1-164.

Sinclair BJ, Cumming JM (2006) The morphology, higher-level phylogeny and classification of the Empidoidea (Diptera). Zootaxa 1180: 1-172.

Steyskal GC, Knutson LV (1981) Empididae. In: McAlpine JF, Peterson BV, Shewell GE, Teskey HJ, Vockeroth JR, Wood DM (Coord) Manual of Nearctic Diptera. Vol. 1. Agriculture Canada Monograph No. 27. 607-624.

Woodley NE (1989) Phylogeny and classification of the "orthorrhaphous" Brachycera. In: McAlpine JF, Wood DM (Eds) Manual of Nearctic Diptera. Vol. 3. Agriculture Canada Monograph No. 32: 1371-1395. 
Yang D, Gaimari SD (2005) Review of the species of Elaphropeza Macquart (Diptera: Empidoidea: Tachydromiinae) from Chinese mainland. Proceedings of the Entomological Society of Washington 107(1): 49-54.

Yang D, Merz B, Grootaert P (2006) Revision of Elaphropeza Macquart from Guangdong, China (Diptera, Hybotidae, Tachydromiinae). Revue Suisse de Zoologie 113(3): 569-578. Yang D, Zhang KY, Yao G and Zhang JH (2007) World catalog of Empididae (Insecta: Diptera). China Agricultural University Press, Beijing, 599 pp. 